\title{
An investigation of carbon nanotubes obtained from the decomposition of methane over reduced $\mathrm{Mg}_{1-x} \mathrm{M}_{x} \mathrm{Al}_{2} \mathrm{O}_{4}$ spinel catalysts
}

\author{
A. Govindaraj \\ CSIR Centre of Excellence in Chemistry, Indian Institute of Science, Bangalore 560012, India \\ E. Flahaut, Ch. Laurent, A. Peigney, and A. Rousset \\ Laboratoire de Chimie des Matériaux Inorganiques, ESA CNRS 5070, Université Paul-Sabatier, \\ 31062 Toulouse cedex 4, France \\ C.N.R. Rao ${ }^{\text {a) }}$ \\ CSIR Centre of Excellence in Chemistry, Indian Institute of Science, Bangalore 560012, India and \\ Jawaharlal Nehru Centre for Advanced Scientific Research, Jakkur P.O., Bangalore 560064, India
}

(Received 9 June 1998; accepted 6 January 1999)

Carbon nanotubes produced by the treatment of $\mathrm{Mg}_{1-x} \mathrm{M}_{x} \mathrm{Al}_{2} \mathrm{O}_{4}(\mathrm{M}=\mathrm{Fe}, \mathrm{Co}$, or $\mathrm{Ni} ; x=0.1,0.2,0.3$, or 0.4 ) spinels with an $\mathrm{H}_{2}-\mathrm{CH}_{4}$ mixture at $1070{ }^{\circ} \mathrm{C}$ have been investigated systematically. The grains of the oxide-metal composite particles are uniformly covered by a weblike network of carbon nanotube bundles, several tens of micrometers long, made up of single-wall nanotubes with a diameter close to $4 \mathrm{~nm}$. Only the smallest metal particles $(<5 \mathrm{~nm})$ are involved in the formation of the nanotubes. A macroscopic characterization method involving surface area measurements and chemical analysis has been developed in order to compare the different nanotube specimens. An increase in the transition metal content of the catalyst yields more carbon nanotubes (up to a metal content of $10.0 \mathrm{wt} \%$ or $x=0.3$ ), but causes a decrease in carbon quality. The best compromise is to use $6.7 \mathrm{wt} \%$ of metal $(x=0.2)$ in the catalyst. Co gives superior results with respect to both the quantity and quality of the nanotubes. In the case of $\mathrm{Fe}$, the quality is notably hampered by the formation of $\mathrm{Fe}_{3} \mathrm{C}$ particles.

\section{INTRODUCTION}

Carbon nanotubes ${ }^{1}$ are attractive materials for use in composites since they exhibit excellent mechanical properties $^{2-8}$ and interesting electrical characteristics ${ }^{9-16}$ that are related to their unidimensional nature. Carbon nanotubes are commonly prepared by arc-discharge between carbon electrodes in an inert gas atmosphere. ${ }^{1,17,18}$ Transition metals are used as catalysts during the arcdischarge to favor the formation of single-shell nanotubes and also to increase their quantity and length. ${ }^{18-24}$ Nevertheless, products so obtained generally are mixtures of nanotubes and several other carbon forms, including a considerable proportion of amorphous carbon and carbon nanoparticles. While purification becomes necessary, it also decreases the nanotube yield to about $2 \% .{ }^{25,26}$ In contrast, laser vaporization of transition metal-graphite rods produces "ropes" of single-wall carbon nanotubes with a yield of more than $70 \% .^{27,28}$

Catalytic decomposition of hydrocarbons ${ }^{29-35}$ and metallocenes $^{36}$ as well as the disproportionation of $\mathrm{CO}^{37-39}$ on small metal particles $(\mathrm{Fe}, \mathrm{Co}, \mathrm{Ni}, \mathrm{Cu}, \mathrm{Mo}$,

\footnotetext{
${ }^{a)}$ Address all correspondence to this author.
}

and $\mathrm{Pt}$ ) produce carbon filaments among which are some lijima-type nanotubes. Several mechanisms proposed for the formation of tubular carbon species by these methods ${ }^{39-43}$ point out that the metal particles are active for nanotube nucleation and growth only if they are sufficiently small $(\leqslant 20 \mathrm{~nm})$. The minimal internal tube diameter that can be obtained by such means corresponds to that of the catalytic particle. Thus, a very small size of the catalyst particles becomes essential for obtaining single-wall nanotubes. Dai et al. ${ }^{39}$ obtained isolated single-wall tubes with diameters ranging between 1 and $5 \mathrm{~nm}$ by the disproportionation of $\mathrm{CO}$ on $\mathrm{Mo}$ particles a few nanometers in size. In order to maximize the nanotube yield with respect to the other forms of carbon, such as carbon nanoparticles and pyrolitic deposits, several authors have investigated the influence of temperature and of the nature of both the catalyst and the conditions of treatment. ${ }^{29,33,37,42}$ In particular, Ivanov et al. ${ }^{33}$ treated a zeolite-supported Co catalyst in a $\mathrm{N}_{2}-\mathrm{C}_{2} \mathrm{H}_{2}$ atmosphere and obtained carbon tubes of $4 \mathrm{~nm}$ diameter $(60 \mu \mathrm{m}$ in length). These authors point out that the longest tubes are also the thickest. Hernadi et al. $^{43}$ showed that Co-zeolite catalysts give better results when prepared by impregnation rather 
than by ion-exchange; these catalysts were superior to $\mathrm{Co} / \mathrm{SiO}_{2}$ catalysts prepared by impregnation.

The metal particles ( $\mathrm{Cr}, \mathrm{Fe}, \mathrm{Co}, \mathrm{Ni}$, and their alloys) obtained by the selective hydrogen reduction of oxide solid solutions are generally smaller than $10 \mathrm{~nm}$ in diameter and were located both inside and on the surface of the grains of the matrix oxides such as $\mathrm{Al}_{2} \mathrm{O}_{3}$, $\mathrm{Cr}_{2} \mathrm{O}_{3}, \mathrm{MgO}$, and $\mathrm{MgAl}_{2} \mathrm{O}_{4}{ }^{44-51}$ When $\mathrm{H}_{2}-\mathrm{CH}_{4}$ gas mixture was used instead of pure $\mathrm{H}_{2}$ for the reduction of $\alpha-\mathrm{Al}_{1.9} \mathrm{Fe}_{0.1} \mathrm{O}_{3}$, pristine $\mathrm{Fe}$ nanoparticles were formed in situ upon reduction. Such metal particles are found to be adequate for the catalytic formation of carbon nanotubes. ${ }^{52}$ The resulting carbon nanotube- $\mathrm{Fe}-\mathrm{Al}_{2} \mathrm{O}_{3}$ composite powder contains a huge amount of singlewall and multiwall nanotubes with diameters in the 1.5$15 \mathrm{~nm}$ range. The nanotubes were arranged in bundles smaller than $100 \mathrm{~nm}$ in diameter and were more than $100 \mu \mathrm{m}$ in length, the total bundle length in a gram of the powder being approximately 100,000 km. Studies of alumina-based materials ${ }^{53,54}$ have shown that an increase in the reduction temperature (from 900 to $1000{ }^{\circ} \mathrm{C}$ ) increases the yield of nanotubes, but decreases the quality. A higher quantity of carbon nanotubes was obtained when $\alpha-\mathrm{Al}_{1.8} \mathrm{Fe}_{0.2} \mathrm{O}_{3}$ was used as the starting material, but $\mathrm{Al}_{2} \mathrm{O}_{3}$ is not a suitable catalyst matrix for use with $\mathrm{Co}$ or $\mathrm{Ni}$. On the other hand, solid solutions between the $\mathrm{MgAl}_{2} \mathrm{O}_{4}$ spinel and $\mathrm{FeAl}_{2} \mathrm{O}_{4}, \mathrm{CoAl}_{2} \mathrm{O}_{4}$, or $\mathrm{NiAl}_{2} \mathrm{O}_{4}$ prepared by the combustion method ${ }^{55}$ followed by $\mathrm{H}_{2}$ reduction gives rise to metal-spinel nanocomposite powders, ${ }^{49,50}$ the combustion method being generally well suited to prepare fine particulate materials. We have therefore considered it most worthwhile to investigate the influence of the nature as well as the content of the transition metal $(\mathrm{Fe}, \mathrm{Co}$, and $\mathrm{Ni}$ ) in spinel solid solutions on the yield and the quality of the carbon nanotubes formed by the decomposition of methane in a hydrogen atmosphere. Furthermore, we have employed surface area measurements to quantify the yield of the nanotubes as well as their quality.

\section{EXPERIMENTAL}

Appropriate amounts of the desired metal nitrates $(\mathrm{Mg}, \mathrm{Al}, \mathrm{Fe}, \mathrm{Co}$, and $\mathrm{Ni}$ ) were mixed in stoichiometric proportions with urea and dissolved in a minimum amount of water in a Pyrex dish. The transition-metal nitrates were substituted for magnesium nitrate with the aim of preparing $\mathrm{Mg}_{1-x} \mathrm{M}_{x} \mathrm{Al}_{2} \mathrm{O}_{4}(\mathrm{M}=\mathrm{Fe}$, Co, or $\mathrm{Ni} ; x=0.1,0.2,0.3$, or 0.4 ) solid solutions. The stoichiometric composition of the redox mixtures was calculated using the total oxidizing and reducing valency of the metal nitrates (oxidizer) and urea (fuel), so that the equivalence ratio was equal to unity. ${ }^{55-58}$ The dish containing the solution was placed in a furnace preheated at $600{ }^{\circ} \mathrm{C}$. The solution immediately started to boil and underwent dehydration. The decomposition of the metal nitrates was accompanied by a large release of gases (oxides of nitrogen and ammonia). The resulting paste frothed and formed a foam which swelled and then blazed. A white flame occurred with the production of a material which swelled to the capacity of the Pyrex dish. The total combustion process was over in less than 5 min. One combustion batch gave about $6 \mathrm{~g}$ of the oxide powder. The combustion products were attritionmilled (2000 rpm, $30 \mathrm{~min}$ ) in an aqueous solution of dispersant using alumina balls and a nylon rotor in a nylon vessel. The product obtained was passed through a sieve using ethanol to wash the alumina balls and the vessel. Excess ethanol was removed by evaporation at $60{ }^{\circ} \mathrm{C}$ in an oven for $24 \mathrm{~h}$. The oxide powders were calcinated in air at $500{ }^{\circ} \mathrm{C}$ for $30 \mathrm{~min}$ in order to remove the contamination caused by erosion of nylon during milling.

The calcinated spinels were treated with a $\mathrm{H}_{2}-$ $\mathrm{CH}_{4}$ gas mixture $\left(18 \mathrm{~mol} \% \mathrm{CH}_{4}\right.$ ) for $6 \mathrm{~min}$ (flow rate $250 \mathrm{sccm}$ ) at $1070{ }^{\circ} \mathrm{C}$, to obtain carbon nanotube-metalspinel powders. The flow gas was dried on $\mathrm{P}_{2} \mathrm{O}_{5}$ and its composition was controlled using mass-flow controllers. The nanocomposite powders containing the various carbon species along with the catalyst powder (metal particles + oxide matrix) were examined by scanning and transmission electron microscopy (SEM and TEM), surface area, and other techniques. The nanocomposite powders (containing the various carbon species) obtained after $\mathrm{H}_{2}-\mathrm{CH}_{4}$ treatment were heated in air at $900{ }^{\circ} \mathrm{C}$ for $2 \mathrm{~h}$ in order to eliminate all or part of the carbon, as required for the specific surface area study.

Powders for SEM examination were sonicated in ethanol, deposited onto an aluminum sample holder, and coated with $\mathrm{Ag}$ to prevent charge accumulation. TEM specimens were sonicated in ethanol, and a drop of the dispersion was deposited onto a holey $\mathrm{Cu}$ grid. Phase detection and identification were performed using x-ray diffraction (XRD) with $\mathrm{CoK}_{\alpha}$ radiation $(\lambda=$ $0.17902 \mathrm{~nm})$. The specific surface areas of the starting spinel oxide powders $\left(S_{s s}\right)$, of the reduced nanocomposite powders obtained after treatment with $\mathrm{H}_{2}-\mathrm{CH}_{4}$ $\left(S_{r}\right)$ and of the powders heated to $900{ }^{\circ} \mathrm{C}$ in air $\left(S_{o}\right)$ were measured by the Brunauer, Emmett, and Teller (BET) analysis method using $\mathrm{N}_{2}$ adsorption at liquid $\mathrm{N}_{2}$ temperature. The carbon content in the reduced composite powders, $\mathrm{C}_{n}$ was determined by flash combustion. For the sake of brevity, the calcinated spinel oxides and the corresponding nanocomposites (obtained after treatment with $\mathrm{H}_{2}-\mathrm{CH}_{4}$ ) will hereafter be denoted by $\mathrm{OM} x$ and $\mathrm{M} x(\mathrm{M}=\mathrm{Fe}, \mathrm{Co}$, or $\mathrm{Ni}$ and $x$ is the compositional coefficient in the starting solid solution), respectively. When discussing the powders containing carbon nanotubes, it is found useful to specify the amount of metallic phase (wt $\%)$ in the composite. Oxide specimens with 
$x=0.1,0.2,0.3$, and 0.4 correspond to composite powders containing 3.3,6.7, 10.0, and $13.3 \mathrm{wt} \%$ of the metallic phase, assuming a total reduction of the transition metal ions (Table I).

\section{RESULTS AND DISCUSSION}

\section{A. Oxide spinels}

\section{X-ray diffraction}

Analysis of the XRD patterns (Figs. 1-3) of the spinel oxide powders $(\mathrm{OM} x)$ reveals the presence of a small amount of $\alpha-\mathrm{Al}_{2} \mathrm{O}_{3}$, in all the specimens. Comparison with the XRD patterns recorded prior to attrition-milling of the powders (not shown) suggests that this is a result of erosion of the alumina balls during milling. Besides $\alpha-\mathrm{Al}_{2} \mathrm{O}_{3}$ only the spinel phase is detected in the OFex specimens (Fig. 1), whereas small amounts of $\mathrm{MgO}$ and $\mathrm{NiO}$ are present in addition to the spinel in the OCox (Fig. 2) and ONix (Fig. 3) specimens, respectively. These results are in agreement with those of Quénard et al. ${ }^{50}$ on similar compounds, showing that the combustion products are lacunar spinels with an excess of trivalent cations of general formula $D_{1-3 a} T_{2+2 a} V_{a} \mathrm{O}_{4}$ ( $D$ : divalent cations, $T$ : trivalent cations, $V$ : vacancies). In the case of $\mathrm{Fe}$-containing oxides, it has been shown that the $\mathrm{Fe}^{2+}$ ions are partly oxidized to $\mathrm{Fe}^{3+}$ ions during the combustion and that the products are monophasic spinels. ${ }^{50}$ In the case of Co- and Ni-containing oxides, a fraction of the $\mathrm{Mg}^{2+}$ and $\mathrm{Ni}^{2+}$ ions, respectively, does not enter the spinel lattice and is present as $\mathrm{MgO}$ and $\mathrm{NiO} .{ }^{49}$

\section{Specific surface area}

Specific surface areas of the attrition-milled oxide powders $\left(S_{s s}\right)$ were found to be as follows. For the

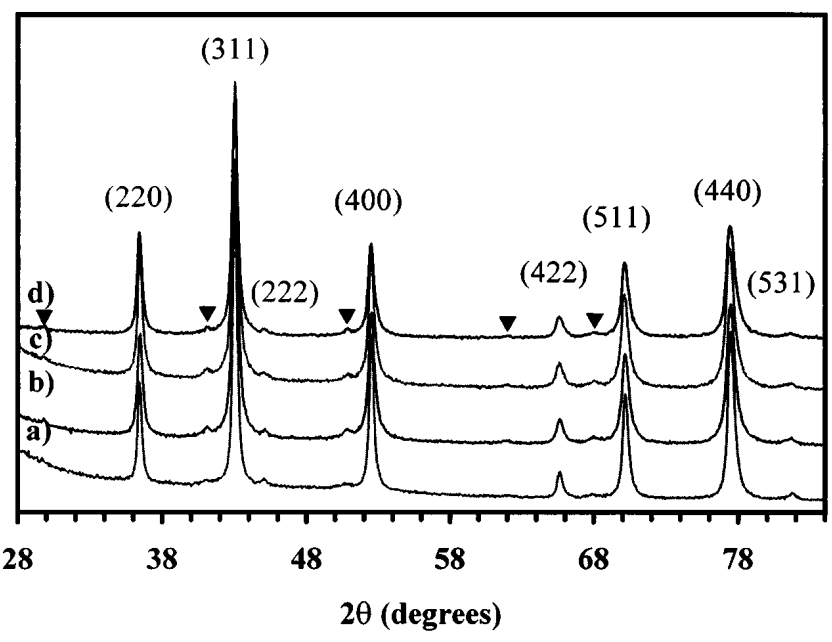

FIG. 1. XRD patterns of the Fe-containing spinels (OFex): (a) $x=$ 0.1 ; (b) $x=0.2$; (c) $x=0.3$; (d) $x=0.4$. Indexed peaks are those of the spinel phase. $(\boldsymbol{\nabla}) \alpha-\mathrm{Al}_{2} \mathrm{O}_{3}$ contamination from the attrition balls.

OFe $x$ specimens, in the $15.7-21.4 \mathrm{~m}^{2} / \mathrm{g}$ range, the value for $\mathrm{OFe} 0.1\left(15.7 \mathrm{~m}^{2} / \mathrm{g}\right)$ is lower than for the others (about $19 \pm 2 \mathrm{~m}^{2} / \mathrm{g}$ ); for the OCox specimens, around $23 \mathrm{~m}^{2} / \mathrm{g}$ for OCo0.1 and OCo0.2 and about $33 \mathrm{~m}^{2} / \mathrm{g}$ for OCo0.3 and OCo0.4; for the ONix specimens, in the $15.1-19.1 \mathrm{~m}^{2} / \mathrm{g}$ range, and the distribution is narrower than for the other oxides (about $17 \pm 2 \mathrm{~m}^{2} / \mathrm{g}$ ). The observed differences probably originate from the combustion process itself which, being quick, does not permit control of the specific surface areas of the combustion products. Attrition-milling of the powders yields a finer grain size and a more homogeneous size distribution, in addition to reducing the specific surface area distribution. The more important surface areas are of the composite powder subjected to $\mathrm{H}_{2}-\mathrm{CH}_{4}$ treatment $\left(S_{r}\right)$ and of the product obtained after oxidizing the carbon in the composite subject to the $\mathrm{H}_{2}-\mathrm{CH}_{4}$ treatment $\left(S_{o}\right)$.

TABLE I. Some characteristics of the carbon nanotubes-metal-spinel nanocomposite powders. ${ }^{\text {a }}$

\begin{tabular}{|c|c|c|c|c|c|c|}
\hline Specimen & Metal content (wt\%) & $S_{r} / \mathrm{m}^{2} \mathrm{~g}^{-1}$ & $S_{o} / \mathrm{m}^{2} \mathrm{~g}^{-1}$ & $\mathrm{C}_{n}(\mathrm{wt} \%)$ & $\Delta S / \mathrm{m}^{2} \mathrm{~g}^{-1}$ & $\Delta S / \mathrm{C}_{n} / \mathrm{m}^{2} \mathrm{~g}^{-1}$ \\
\hline $\mathrm{Fe} 0.1$ & 3.3 & 7.1 & 4.1 & 1.8 & 3.0 & 167 \\
\hline $\mathrm{Fe} 0.2$ & 6.7 & 18.2 & 10.5 & 5.8 & 7.7 & 133 \\
\hline $\mathrm{Fe} 0.3$ & 10.0 & 20.6 & 11.9 & 9.2 & 8.7 & 95 \\
\hline $\mathrm{Fe} 0.4$ & 13.3 & 20.1 & 11.4 & 11.8 & 8.7 & 74 \\
\hline $\mathrm{Co} 0.1$ & 3.3 & 19.2 & 10.0 & 2.6 & 9.2 & 354 \\
\hline $\mathrm{Co} 0.2$ & 6.7 & 23.3 & 10.5 & 3.8 & 12.8 & 337 \\
\hline $\mathrm{Co} 0.3$ & 10.0 & 27.5 & 13.8 & 5.1 & 13.7 & 269 \\
\hline $\mathrm{Co} 0.4$ & 13.3 & 29.2 & 15.6 & 7.1 & 13.6 & 192 \\
\hline $\mathrm{NiO} .1$ & 3.3 & 11.7 & 9.4 & 1.2 & 2.3 & 192 \\
\hline $\mathrm{NiO} 0.2$ & 6.7 & 13.5 & 9.2 & 2.0 & 4.3 & 215 \\
\hline $\mathrm{Ni} 0.3$ & 10.0 & 16.0 & 9.4 & 3.3 & 6.6 & 200 \\
\hline $\mathrm{Ni} 0.4$ & 13.3 & 16.0 & 9.6 & 5.2 & 6.4 & 123 \\
\hline
\end{tabular}

${ }^{\mathrm{a}} \mathrm{C}_{n}$ : carbon content; $S_{r}, S_{o}$ : specific surface areas of the composite powder after $\mathrm{H}_{2}-\mathrm{CH}_{4}$ treatment containing nanotubes and the oxidized powder, respectively; $\Delta S=S_{r}-S_{o}$ : surface area of carbon for one gram of composite powder, representing the quantity of nanotubes; $\Delta S / \mathrm{C}_{n}: s p e c i f i c$ surface area of carbon, representing the quality of nanotubes. 


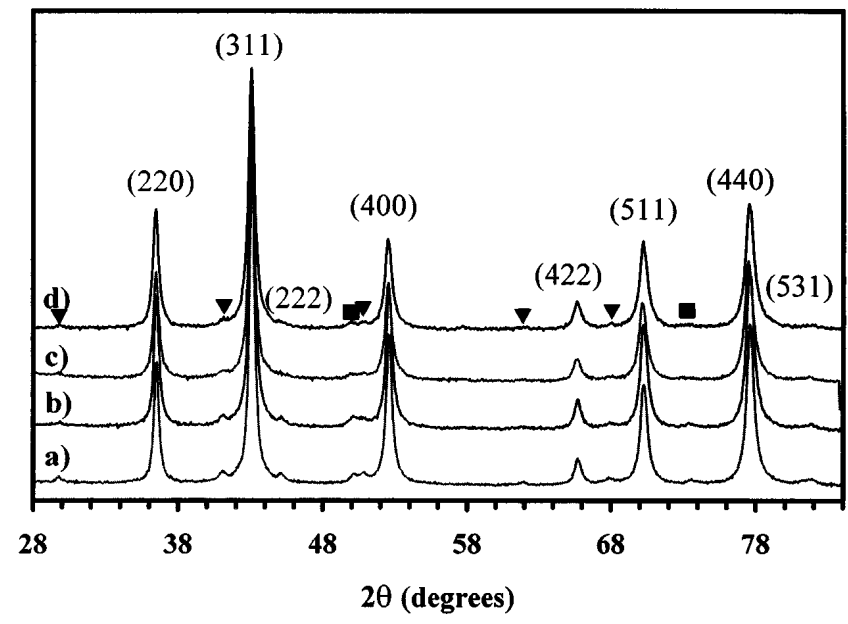

FIG. 2. XRD patterns of the Co-containing spinels (OCox): (a) $x=$ 0.1 ; (b) $x=0.2$; (c) $x=0.3$; (d) $x=0.4$. Indexed peaks are those of the spinel phase. $(\boldsymbol{\nabla}) \alpha-\mathrm{Al}_{2} \mathrm{O}_{3}$ contamination from the attrition

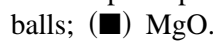

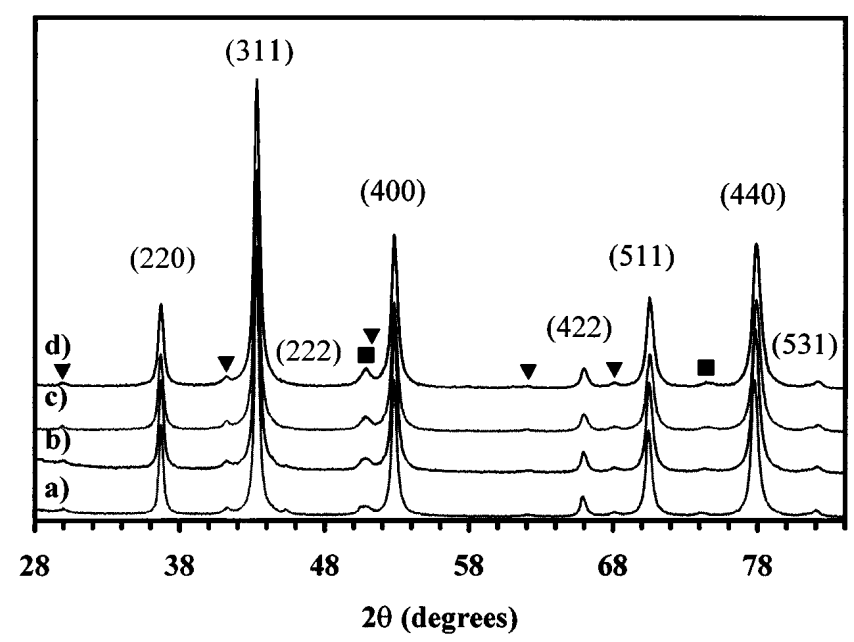

FIG. 3. XRD patterns of the Ni-containing spinels (ONix): (a) $x=$ 0.1 ; (b) $x=0.2$; (c) $x=0.3$; (d) $x=0.4$. Indexed peaks are those of the spinel phase. $(\boldsymbol{\nabla}) \alpha-\mathrm{Al}_{2} \mathrm{O}_{3}$ contamination from the attrition

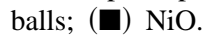

\section{B. Carbon nanotubes}

\section{X-ray diffraction}

Analysis of the XRD patterns (Figs. 4-6) of the reduced catalyst specimens $(\mathrm{M} x)$ reveals the presence of the metallic phase besides the spinel matrix. The $\alpha-\mathrm{Fe}$ (110) reflection $(d=0.203 \mathrm{~nm})$ is not clearly detected because of its superimposition with the (400) reflection of the spinel phase $(d=0.202 \mathrm{~nm})$ (Fig. 4). The intensity of this peak relative to the spinel (311) peak, however, suggests the presence of $\alpha-\mathrm{Fe}$. Interestingly, $\mathrm{Fe}_{3} \mathrm{C}$ (cementite) is detected in addition to $\alpha-\mathrm{Fe}$ and the spinel, the intensity of the corresponding peaks increasing with the increase in Fe content. A wide peak which could correspond to the distance between

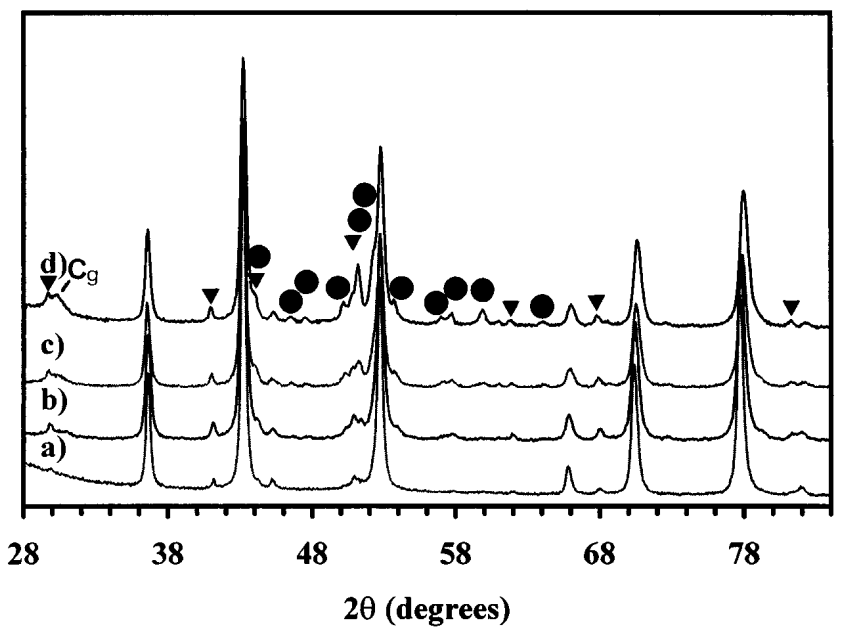

FIG. 4. XRD patterns of the Fe-containing nanocomposite powders after treatment with $\mathrm{H}_{2}-\mathrm{CH}_{4}$ at $1070{ }^{\circ} \mathrm{C}$ (Fex): (a) $x=0.1$;

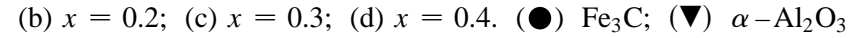
contamination from the attrition balls. $\mathrm{Cg}$ corresponds to $d_{002}$ in multiwall nanotubes and/or in graphite; other peaks: spinel matrix. The $\alpha-\mathrm{Fe}$ (110) peak is masked by the (400) spinel peak at $2 \Theta$ equal to about $52^{\circ}$.

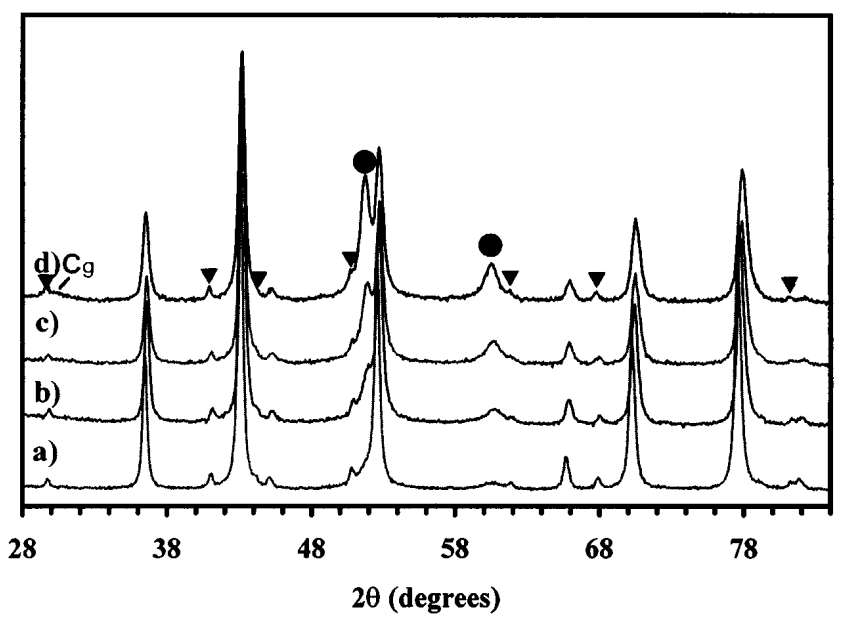

FIG. 5. XRD patterns of the Co-containing nanocomposite powders after treatment with $\mathrm{H}_{2}-\mathrm{CH}_{4}$ at $1070{ }^{\circ} \mathrm{C}$ (Cox): (a) $x=0.1$; (b) $x=0.2$; (c) $x=0.3$; (d) $x=0.4$. (O) $\epsilon-\mathrm{Co}$; ( ( ) $\alpha-\mathrm{Al}_{2} \mathrm{O}_{3}$ contamination from the attrition balls. $\mathrm{Cg}$ corresponds to $d_{002}$ in multiwall nanotubes and/or in graphite; other peaks: spinel matrix.

graphene layers $\left(d_{002}=0.34 \mathrm{~nm}\right)$ is also detected. Since neither the $(h k 0)$ nor the other $(h k l)$ reflections (which would have much smaller intensities for nanotubes as well as for graphite $^{59}$ ) are found in the XRD patterns, it is not possible to distinguish graphite from the nanotubes.

The (111) reflections due to $\epsilon-\mathrm{Co} \quad\left(d_{111}=\right.$ $0.205 \mathrm{~nm})$ and $\mathrm{Ni}\left(d_{111}=0.203 \mathrm{~nm}\right)$ are difficult to detect, in the M0.1 and M0.2 specimens, because of the overlap with the spinel (400) reflection $\left(d_{400}=0.202\right.$ $\mathrm{nm})$. A shoulder is observed on the low-angle side of this peak and is more and more apparent with the 


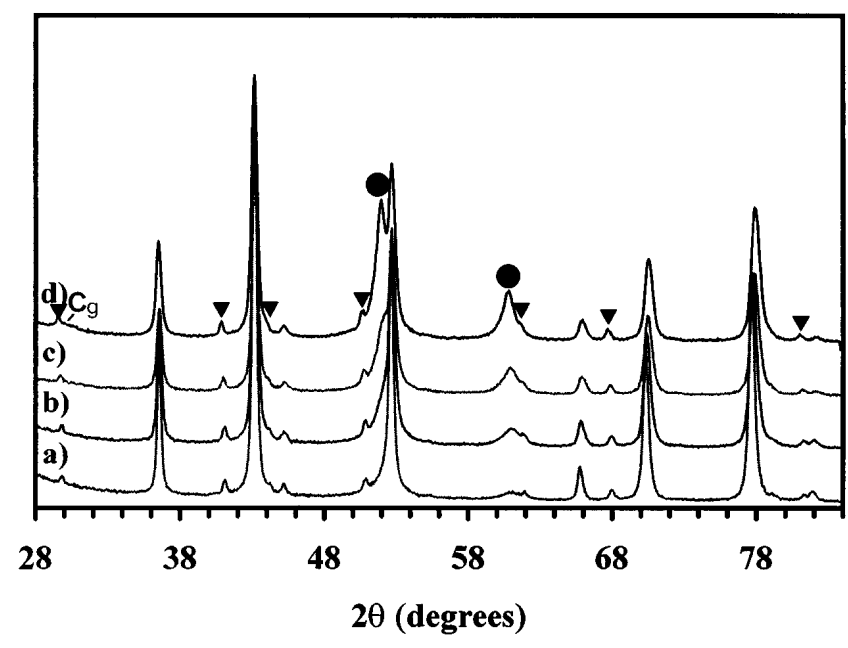

FIG. 6. XRD patterns of the Ni-containing nanocomposite powders after treatment with $\mathrm{H}_{2}-\mathrm{CH}_{4}$ at $1070{ }^{\circ} \mathrm{C}$ (Nix): (a) $x=0.1$; (b) $x=0.2$; (c) $x=0.3$; (d) $x=0.4$. (O) Ni; ( $) \alpha-\mathrm{Al}_{2} \mathrm{O}_{3}$ contamination from the attrition balls. Cg corresponds to $d_{002}$ in multiwall nanotubes and/or in graphite; other peaks: spinel matrix.

increase in metal content (Figs. 5 and 6). Furthermore, the $\epsilon-\mathrm{Co}$ (200) peak and the $\mathrm{Ni}$ (200) peak are clearly detected in all XRD patterns. In agreement with the results reported by Quénard et al., ${ }^{49,50}$ the intensities of the $\mathrm{MgO}(\mathrm{NiO})$ peaks are lower than in the XRD patterns of the corresponding oxides, indicating that some $\mathrm{Mg}^{2+}$ ions $\left(\mathrm{Ni}^{2+}\right.$ ions) progressively enter the spinel lattice in place of the freshly reduced $\mathrm{Co}^{2+}$ ions $\left(\mathrm{Ni}^{2+}\right.$ ions). Carbide phases are not detected for the $\mathrm{Cox}$ and Nix composites. The graphene peak, if present, is much less intense than in the $\mathrm{Fe} x$ powders.

Quénard et al. ${ }^{49,50,60}$ have reported that the size distribution of the $\mathrm{Co}$ and $\mathrm{Ni}$ particles formed upon $\mathrm{H}_{2}$ reduction at $1000{ }^{\circ} \mathrm{C}$ is unimodal (approximately $15 \mathrm{~nm}$ for products corresponding to $\mathrm{Co} 0.2$ and Ni0.2) whereas that of the Fe particles is multimodal, with a second distribution of much larger particles (approximately $200 \mathrm{~nm}$ ) dispersed on the surface of the matrix grains. Such particles could be too large for the formation of carbon nanotubes and tend to give rise to $\mathrm{Fe}_{3} \mathrm{C}$. They could also be covered by graphene layers.

\section{Carbon content}

Independent of the transition metal $(\mathrm{Fe}, \mathrm{Co}$, and $\mathrm{Ni})$, the carbon content $\left(\mathrm{C}_{n}\right)$ increases with the increase in metal content in the starting solid solution (Fig. 7 and Table I). $\mathrm{C}_{n}$ is in the 1.8-11.8 wt\% range for the $\mathrm{Fe} x$ composites, the value for $\mathrm{Fe} 0.1$ (1.8 wt\%) being markedly lower than for the others. $\mathrm{C}_{n}$ is in the 2.6$7.1 \mathrm{wt} \%$ range for the Cox composites and in the 1.2$5.2 \mathrm{wt} \%$ range for the Nix specimens. Clearly, the nature of the transition metal strongly affects the conversion of $\mathrm{CH}_{4}$ into carbon species during the reduction step.

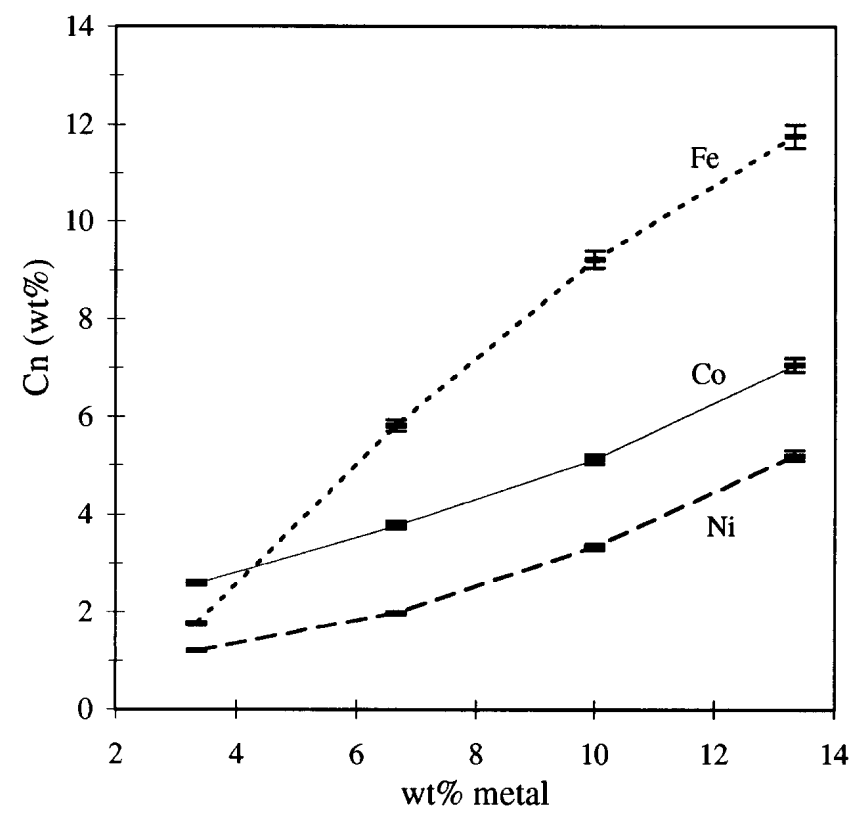

FIG. 7. The carbon content $\left(\mathrm{C}_{n}\right)$ versus the transition metal content in the composite powders.

Fe provides the highest yield of carbon and $\mathrm{Ni}$ the lowest, Co giving intermediate values. These results are in qualitative agreement with those reported by Jablonski et al. ${ }^{61}$ for the deposition of various carbonaceous gases on $\mathrm{Fe}, \mathrm{Co}$, and $\mathrm{Ni}$ foils.

\section{Electron microscopy}

SEM observations of the reduced composite powders (Fig. 8) show that the grains of the oxide matrix, between 0.1 and $2 \mu \mathrm{m}$ in diameter, are uniformly covered by a weblike network of carbon filaments [Fig. 8(a)], several tens of micrometers long, showing that the reduced powders retain the shape of the reduction vessel. Some nanoparticles, most of which correspond to the metal or the metal carbide covered by a few graphene layers, are observed on the matrix grains. Some of the particles may be onion-like carbon nanostructures.$^{53} \mathrm{De}$ pending on the nature and quantity of the catalyst, some differences are revealed in the high-magnification SEM images. In the case of the Fe 0.2 sample [Fig. 8(b)], most of the carbon filaments are actually bundles comprising smaller ones. These filaments do not exceed $50 \mathrm{~nm}$ in diameter, some being smaller than $10 \mathrm{~nm}$. In the case of the $\mathrm{Fe} 0.4$ sample, ribbons and other carbon forms [Fig. 8(c)] appear besides the filaments. It was difficult to identify the carbon filaments by SEM in the Co0.2 samples [Fig. 8(d)], probably because the diameters are much smaller and fewer bundles are formed. Most of the filaments are held tight between matrix grains and join each other at nonzero angles. In contrast, bundles clearly appear in the Co0.4 sample. They sometimes 

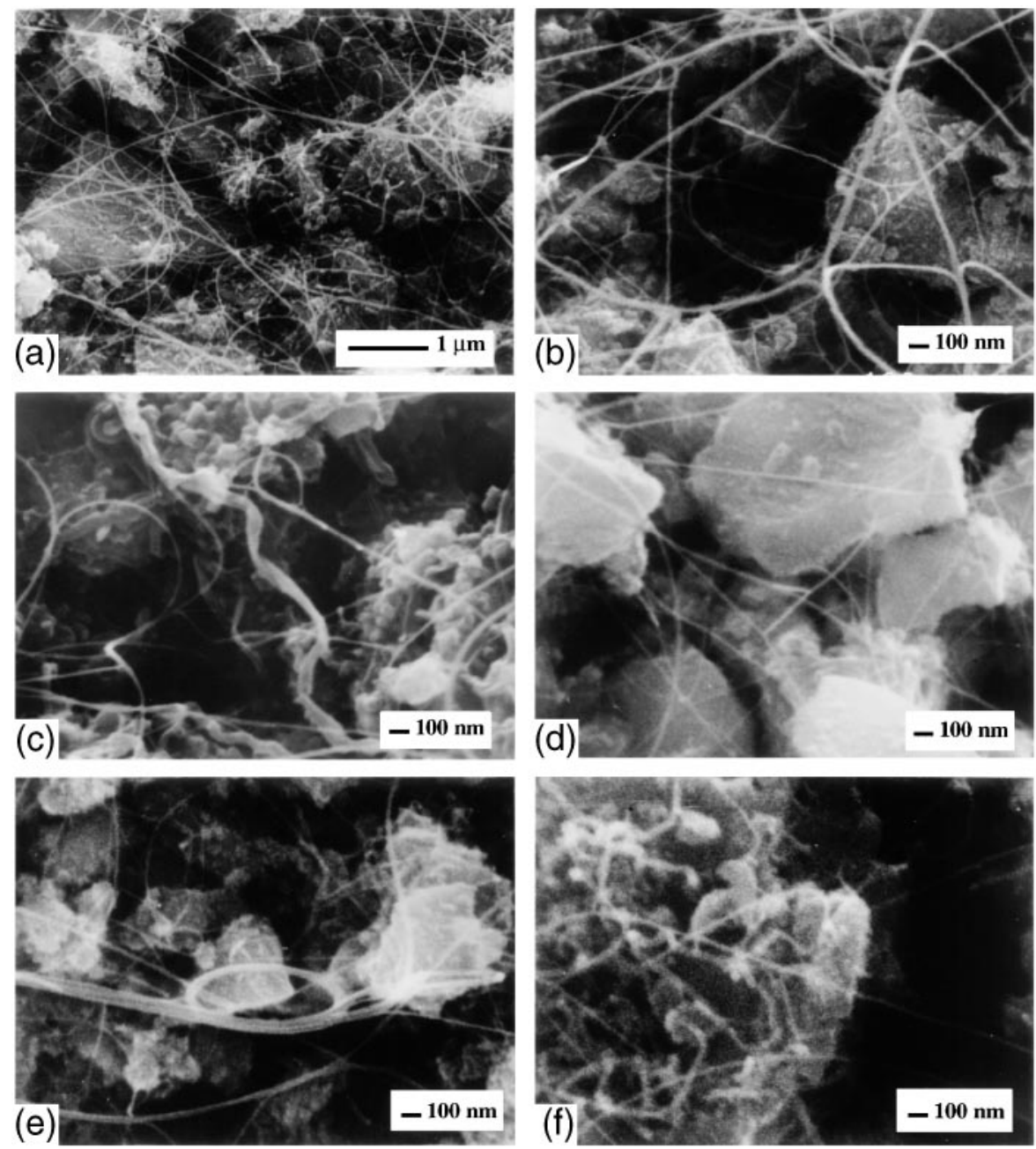

FIG. 8. SEM images of the nanocomposite powders subjected to $\mathrm{H}_{2}-\mathrm{CH}_{4}$ treatment at $1070{ }^{\circ} \mathrm{C}$ : (a) $\mathrm{Fe} 0.2$; (b) $\mathrm{Fe} 0.2$; (c) $\mathrm{Fe} 0.4$; (d) $\mathrm{Co} 0.2$; (e) Co0.4; (f) Ni0.2.

form buckles, one of which looking like a ring is shown in Fig. 8(e), but ribbons and short filaments of large diameter were not observed. In the case of the Ni0.2 sample, short, large-diameter filaments appear on some of the matrix grains, in addition to the long, smalldiameter filaments [Fig. 8(f)].

Some of the composite powders were examined by TEM. The influence of the nature and content of the metal catalyst on the carbon species formed cannot be assessed solely from TEM studies. The TEM images in Fig. 9 represent typical examples of the different species present in the composite powders. In the $\mathrm{Fe} 0.2$ sample [Fig. 9(a)], we see that the bundles are indeed made up of carbon nanotubes, most of which appear to be singlewalled, with diameters close to $4 \mathrm{~nm}$. Smaller nanotubes $(2.5 \mathrm{~nm})$ are also observed. The nanotubes are flexible and some are sharply twisted and bent. Most of the nanotubes appeared to be unstable under the electron beam. Amorphous carbon can be seen decorating the surface of the nanotubes in some places. $\mathrm{Fe}$ and/or $\mathrm{Fe}_{3} \mathrm{C}$ particles between 5 and $20 \mathrm{~nm}$ in diameter (appearing as dark spots in the image), covered by graphene layers, also decorate the external surfaces of the nanotubes. Clearly, particles in this size range are not connected with the inner part of the nanotubes. With smaller catalyst particles, however, the diameters of the tubes would be small and we therefore do not observe the tips of the nanotubes. A hollow carbon fiber (inner diameter approximately $5 \mathrm{~nm}$ ) exhibiting the fishbone structure described by Baker and Rodriguez ${ }^{32}$ was also observed in the $\mathrm{Fe} 0.2$ sample [Fig. 9(b)]. It would, however, appear that the mechanism responsible for the formation of the carbon nanotubes in the present study is different from that proposed by Baker and Rodriguez. ${ }^{32}$ In Fig. 9(b), we also see thin nanotubes and a hollow carbon particle.

A two-layer nanotube (external diameter equal to $2 \mathrm{~nm}$ ) is seen bridging two metal-oxide grains in the image of the Co0.1 sample in Fig. 9(c). An image of the Co0.2 specimen [Fig. 9(d)] shows nanotube bundles 

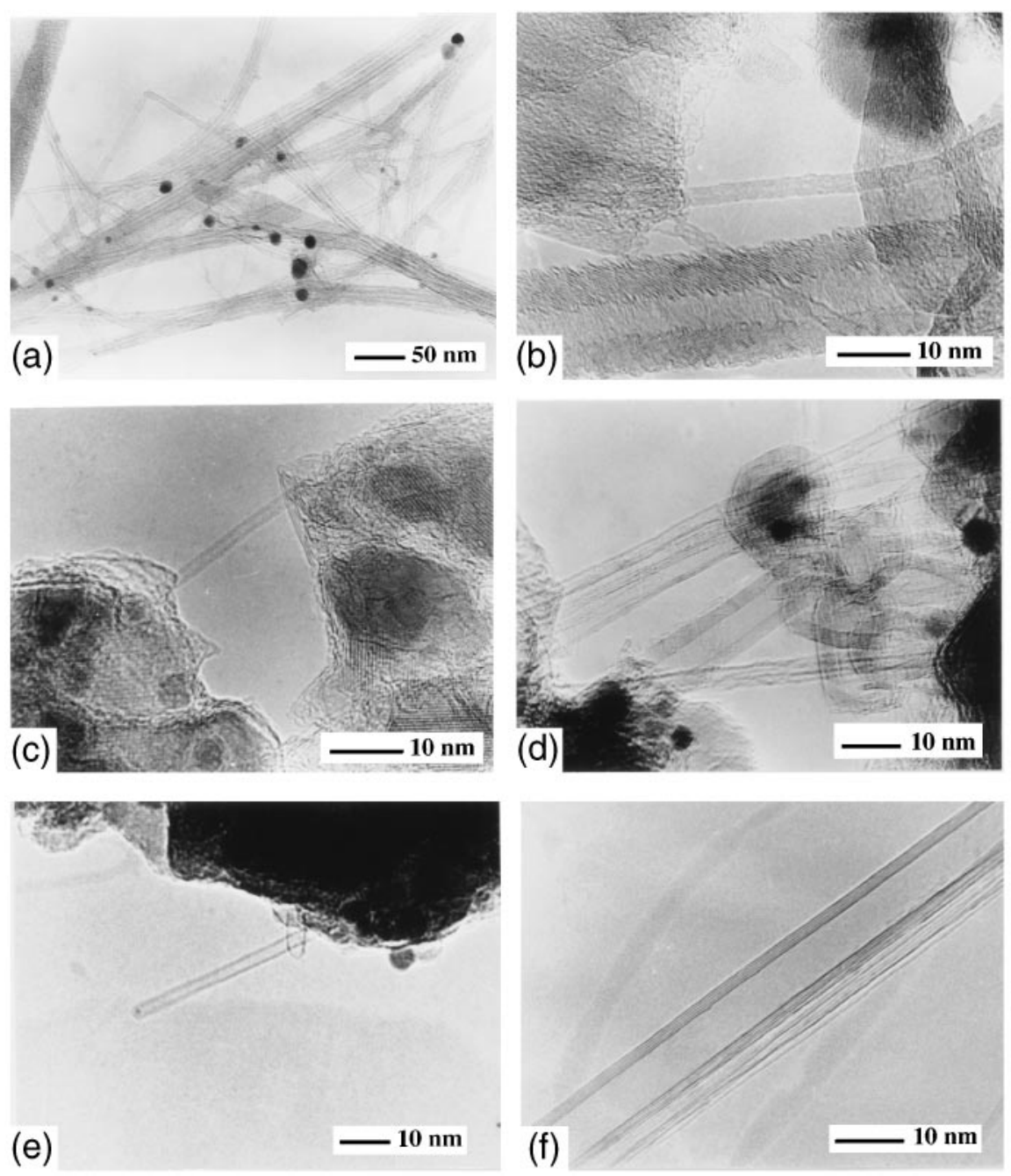

FIG. 9. TEM images of the nanocomposite powders subjected to $\mathrm{H}_{2}-\mathrm{CH}_{4}$ treatment at $1070{ }^{\circ} \mathrm{C}$ : (a) $\mathrm{Fe} 0.2 ;$ (b) $\mathrm{Fe} 0.2 ;$ (c) $\mathrm{Co0} .1 ;$ (d) $\mathrm{Co0} .2$; (e) $\mathrm{Ni0.2;} \mathrm{(f)} \mathrm{Ni0.2.}$

and carbon cages, one of which contains a Co particle $10 \mathrm{~nm}$ in diameter, as well as a closed multiwall tube. There is no catalyst particle at the tip of this tube and the number of concentric layers varies along its length. A coating of amorphous carbon is present in the area between a 9-layer and a 7-layer nanotube section. These results suggest that the extension and thickening of the nanotubes may occur partly by island growth of graphene basal planes on the existing tube surfaces acting as templates. ${ }^{19,62}$ The nanotube may also have been damaged by ultrasonic treatment used for TEM specimen preparation. In contrast, observation of the image of the Ni0.2 powder reveals a closed nanotube about $2.5 \mathrm{~nm}$ in diameter with a catalyst particle at the tip [Fig. 9(e)]. Thus the size of the catalyst particle could be evaluated to be approximately $2 \mathrm{~nm}$ by comparison with the inner diameter of the tube. A 5 wall nanotube with a relatively large inner diameter (approximately $6 \mathrm{~nm}$ ) observed in the image of Ni0.2 is shown in Fig. 9(f).
A large proportion of the carbon nanotubes found in the present study appear to be similar to those described by Iijima. This is related to the small size and the nature of the size distribution of the metal particles obtained on reduction of the oxide solid solutions. This observation is consistent with the results of Dai et al. ${ }^{39}$ who report that large Mo particles, fully covered by graphite, were inactive for nanotube formation by $\mathrm{CO}$ disproportionation. These authors propose that the formation of single-wall nanotubes depends crucially on the very small size of the Mo particles. In the present study, we find both singlewall and multiwall nanotubes because of the presence of a distribution in the size of the catalyst particles.

\section{Specific surface area measurements}

The difference $\Delta S=S_{r}-S_{o}$ between the specific surface area of the nanocomposite powder $\left(S_{r}\right)$ and that of the same powder after oxidation in air at $900{ }^{\circ} \mathrm{C}\left(S_{o}\right)$ essentially represents the quantity of nanotube bundles 
in the composite powder ${ }^{52,53}$ In Fig. 10 and Table I, we have presented the $\Delta S$ values of various samples. $\Delta S$ increases with the increase in transition metal content up to $10 \mathrm{wt} \%$ (M0.3) and saturates for a higher metal content (M0.4). It is noteworthy that $\Delta S$ values are much higher for Co samples $\left(9.2-13.6 \mathrm{~m}^{2} / \mathrm{g}\right)$ than for $\mathrm{Fe}\left(3.0-8.7 \mathrm{~m}^{2} / \mathrm{g}\right)$ and $\mathrm{Ni}\left(2.3-6.4 \mathrm{~m}^{2} / \mathrm{g}\right)$ samples. The markedly low $\Delta S$ for $\mathrm{Fe} 0.1$ could be due to the low specific surface area of the corresponding solid solution (Table I).

The values of $\Delta S / \mathrm{C}_{n}$ are useful to obtain a better understanding of the nature of the nanotubes. The increase in specific surface area per gram of carbon, $\Delta S / \mathrm{C}_{n}$, can be taken to represent the quality of the nanotubes, a higher value denoting a smaller average tube diameter and/or more carbon in tubular form..$^{52,53}$ The $\Delta S / \mathrm{C}_{n}$ values of the samples studied by us are reported in Fig. 11 and in Table I. In the case of the Fex and Cox specimens, $\Delta S / \mathrm{C}_{n}$ decreases with the increase in metal content whereas for $\mathrm{Ni} x$ powders a maximum is observed for Ni0.2. Interestingly, $\Delta S / \mathrm{C}_{n}$ values are much higher for $\mathrm{Co}\left(192-354 \mathrm{~m}^{2} / \mathrm{g}\right)$ than for $\mathrm{Fe}$ $\left(74-167 \mathrm{~m}^{2} / \mathrm{g}\right)$ and $\mathrm{Ni}\left(123-215 \mathrm{~m}^{2} / \mathrm{g}\right)$ samples. The increase in specific surface area upon the catalytic formation of carbon nanofibers reported in the literature ${ }^{63,64}$ are in qualitative agreement with the present results. Hernadi et al. $^{43}$ have reported values of 312 and $653 \mathrm{~m}^{2} / \mathrm{g}$ for carbon nanotubes treated with $\mathrm{KMnO}_{4} / \mathrm{H}_{2} \mathrm{SO}_{4}$ followed by HF. The larger surface areas are because they take into account the inner surfaces, due to the opening of the tubes by the acid. ${ }^{65}$

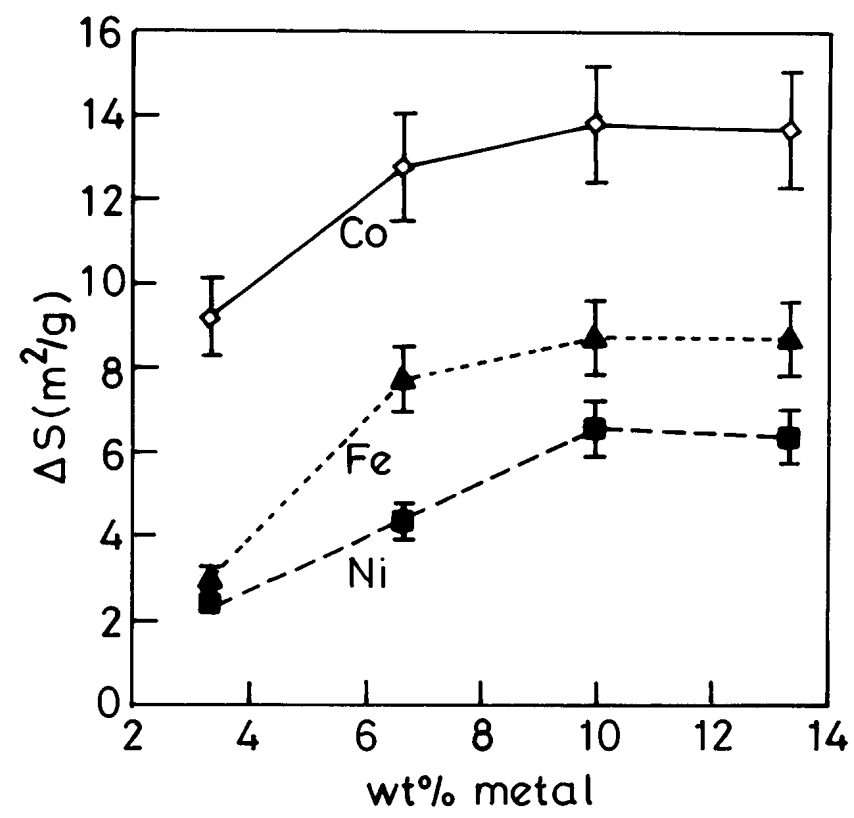

FIG. 10. $\Delta S=S_{n}-S_{s s}$ versus the transition metal content for the various composite powders.

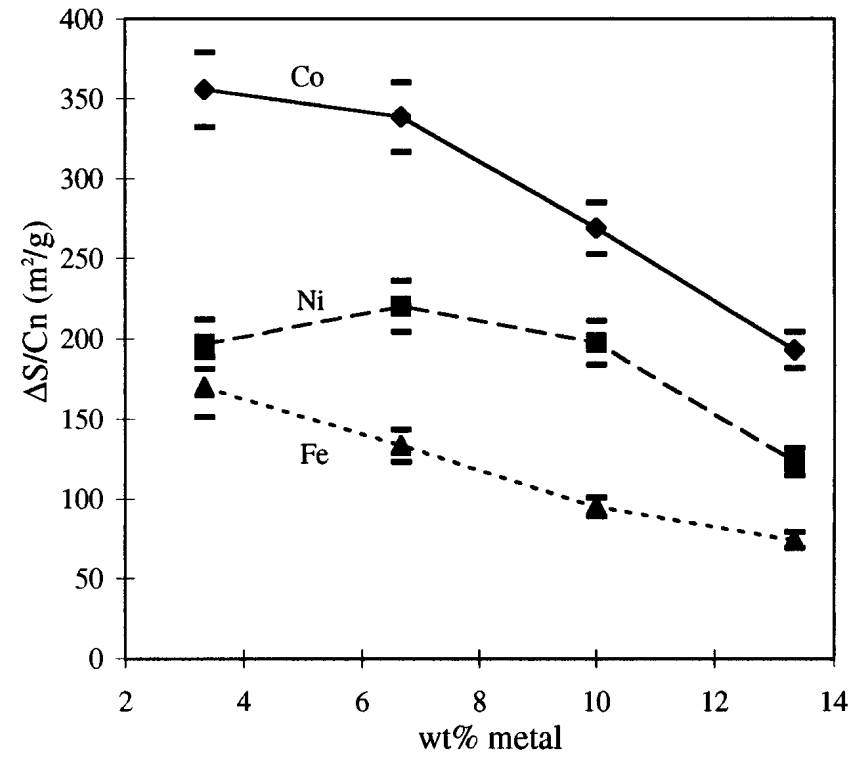

FIG. 11. $\Delta S / \mathrm{C}_{n}$ versus the transition metal content for the various composite powders.

Analysis of the above results shows that increasing the metal content in the catalyst up to $10 \mathrm{wt} \%$ yields more carbon nanotubes owing to the presence of a greater number of catalytically active metal particles on the surfaces of the oxide grains. A further increase in metal content was not effective because it gives rise to larger metal particles covered by graphene layers, which would be inactive for nanotube formation. The carbon quality decreases with the increase in metal content, partly because multiwall tubes are obtained in greater proportion rather than single-wall tubes with higher metal content due to a higher average size of the catalyst particles. These results show that a compromise has to be made between quantity and quality of the nanotubes. A good compromise could be $6.7 \mathrm{wt} \%$ of the transition metal (i.e., M0.2).

Among the different metals, Co appears to be the best catalyst with respect to both the quantity and quality of the nanotubes. Fe yields more carbon nanotubes than $\mathrm{Ni}$, but the quality is hampered by the formation of $\mathrm{Fe}_{3} \mathrm{C}$ particles. Thus, the present results show that the metallic particles, and not the carbide particles, are the active species for the formation of carbon nanotubes, in contrast to the suggestion of Ivanov et al. ${ }^{33}$ In addition, the high proportion of large Fe particles (approximately $200 \mathrm{~nm}$ ) formed on reduction of the spinel ${ }^{49,50,60}$ would be inactive for nanotube formation whether they are simply covered by graphene layers or form the carbide. Since no significant difference was observed regarding the size distribution of the metal particles in $\mathrm{Co}-$ and $\mathrm{Ni}-\mathrm{MgAl}_{2} \mathrm{O}_{4}$ compositions prepared by reduction in pure $\mathrm{H}_{2},{ }^{49}$ the difference in the yields of carbon nanotubes in the present study reflects an intrinsic effect due to differences in the chemical nature of these metals. 


\section{CONCLUSIONS}

Carbon nanotubes are obtained in mixture with particles of the metal and the oxide spinel, by the treatment of $\mathrm{Mg}_{1-x} \mathrm{M}_{x} \mathrm{Al}_{2} \mathrm{O}_{4}(\mathrm{M}=\mathrm{Fe}$, Co, or $\mathrm{Ni} ; x=$ $0.1,0.2,0.3$, or 0.4 ) catalysts with $\mathrm{H}_{2}-\mathrm{CH}_{4}$ mixtures at $1070{ }^{\circ} \mathrm{C}$. In the case of $\mathrm{Fe}$, formation of $\mathrm{Fe}_{3} \mathrm{C}$ particles is observed in addition to the metallic particles. Electron microscopy observations reveal that the grains of the metal-oxide composites are uniformly covered by a weblike network of carbon nanotube bundles, several tens of micrometers long. Most of the nanotubes are single-walled with a diameter close to $4 \mathrm{~nm}$. The nanotubes thus have a high aspect ratio and appear to be flexible. Amorphous carbon is present at the surface of some of the nanotubes. TEM observations suggest that the mechanism for nanotube formation by the process employed in the present study is distinctly different from that proposed for the synthesis of hollow carbon fibers. However, the yarmulke mechanism involving the formation of a graphitic cap and template growth $^{39}$ is likely to be applicable. Only the smallest metal particles $(<5 \mathrm{~nm})$ seem to be connected with the formation of nanotubes. Macroscopic characterization based on chemical analysis and specific surface area measurements helps to compare the quality of different specimens. Such study shows that an increase in the transition metal content yields more carbon nanotubes up to a metal content of $10 \mathrm{wt} \%(x=0.3)$, but decreases the quality. A compromise composition of the catalyst could involve $6.7 \mathrm{wt} \%$ of metal $(x=0.2)$. Co gives superior results with respect to both the quantity and quality parameters. In the case of $\mathrm{Fe}$, the quality of the obtained carbon is notably hampered by the formation of $\mathrm{Fe}_{3} \mathrm{C}$ particles. The observed differences between the $\mathrm{Co}$ and $\mathrm{Ni}$ specimens point to the important role of the metal. Directions for future work include the study of the formation of carbon nanotubes in composite powders containing nanoparticles of $\mathrm{Fe} / \mathrm{Co}, \mathrm{Fe} / \mathrm{Ni}$, and $\mathrm{Co} / \mathrm{Ni}$ alloys.

\section{ACKNOWLEDGMENTS}

The authors would like to thank Dr. O. Quénard for his help in the preparation of the oxide solid solutions and Mr. L. Datas for his assistance in the TEM observations. The financial support of the Indo-French Centre for the Promotion of Advanced Research (New Delhi) is gratefully acknowledged.

\section{REFERENCES}

1. S. Iijima, Nature 354, 56 (1991).

2. P. Calvert, Nature 357, 365 (1992).

3. P. M. Ajayan, O. Stephan, C. Colliex, and D. Trauth, Science 265, 1212 (1994)
4. R. S. Ruoff and D. C. Lorents, Carbon 33, 925 (1995).

5. S. B. Sinnott, C.T. White, and D.W. Brenner, in Science and Technology of Fullerene Materials, edited by P. Bernier, D.S. Bethune, L. Y. Chiang, T. W. Ebbesen, R. M. Metzger, and J. W. Mintmire (Mater. Res. Soc. Symp. Proc. 359, Pittsburgh, PA, 1995), p. 241.

6. J. F. Despres, E. Daguerre, and K. Lafdi, Carbon 33, 87 (1995).

7. S. Iijima, Ch. Brabec, A. Maiti, and J. Bernholc, J. Phys. Chem. 104, 2089 (1996).

8. M. M. J. Treacy, T.W. Ebbesen, and J. M. Gibson, Nature 381, 678 (1996).

9. N. Hamada, S. Sawada, and A. Oshiyama, Phys. Rev. Lett. 68, 1579 (1994).

10. J. W. Mintmire, B. I. Dunlap, and C. T. White, Phys. Rev. Lett. 68, 631 (1992).

11. L. Langer, L. Stockman, J.P. Heremans, V. Bayot, C. H. Olk, C. Van Haesendonck, Y. Bruynseraede, and J. P. Issi, J. Mater. Res. 9, 927 (1994).

12. Y. Nakayama, S. Akita, and Y. Shimada, Jpn. J. Appl. Phys. 34, L10 (1995).

13. A. Yu. Kasumov, I. I. Khodos, P. M. Ajayan, and C. Colliex, Europhys. Lett. 34, 429 (1996).

14. T. W. Ebbesen, H. J. Lezec, H. Hiura, J. W. Bennett, H. F. Ghaemi, and T. Thio, Nature 382, 54 (1996).

15. H. Dai, E. W. Wong, and C. M. Lieber, Science 272, 523 (1996).

16. S. J. Tans, M. H. Devoret, H. Dai, A. Thess, R.E. Smalley, L. J. Geerligs, and C. Dekker, Nature 386, 474 (1997).

17. T. W. Ebbesen and P. M. Ajayan, Nature 358, 220 (1992).

18. C. N. R. Rao, R. Seshadri, R. Sen, and A. Govindaraj, Mater. Sci. Engg. R15, 209 (1995).

19. S. Iijima and T. Ichihashi, Nature 363, 603 (1993).

20. D. S. Bethune, C. H. Kiang, M. S. de Vries, G. Gorman, R. Savoy, J. Vasquez, and R. Beyers, Nature 363, 605 (1993).

21. C.H. Kian, W.A. Goddard III, R. Beyers, J.R. Salem, and D. Bethune, J. Phys. Chem. Solids 57, 35 (1996).

22. S. Seraphin and D. Zhou, Appl. Phys. Lett. 64, 2087 (1994).

23. C. Guerret-Plecourt, Y. Le Bouar, A. Loiseau, and H. Pascard, Nature 372, 761 (1994).

24. C. Journet, W. K. Maser, P. Bernier, A. Loiseau, M. Lamy de la Chapelle, S. Lefrant, P. Deniard, R. Lee, and J.E. Fisher, Nature 388, 756 (1997).

25. T.W. Ebbesen, P. M. Ajayan, H. Hiura, and K. Tanigaki, Nature 367, 519 (1992).

26. K. Tohji, T. Goto, H. Takahashi, Y. Shinoda, N. Shimizu, B. Jeyadevan, I. Matsuoka, Y. Saito, A. Kasuhka, T. Oshuna, K. Hiraga, and Y. Nishima, Nature 383, 679 (1996).

27. T. Guo, P. Nikolaev, A. Thess, D. T. Colbert, and R. E. Smalley, Chem. Phys. Lett. 243, 49 (1995).

28. A. Thess, R. Lee, P. Nikolaev, H. Dai, P. Petit, J. Robert, C. Xu, Y. H. Lee, S. G. Kim, A. G. Rinkler, D. T. Colbert, G. E. Scuseria, D. Tomanek, J.E. Fisher, and R.E. Smalley, Science 273, 483 (1996).

29. A. Oberlin, M. Endo, and T. Koyama, J. Cryst. Growth 32, 335 (1976).

30. F. Benissad-Aissani and P. Gadelle, Carbon 31, 21 (1993).

31. M. J. Yacaman, M. M. Yoshida, L. Rendon, and J. G. Santiesteban, Appl. Phys. Lett. 62, 657 (1993).

32. R. T. K. Baker and N. Rodriguez, in Novel Forms of Carbon II, edited by C. L. Renschler, D. M. Cox, J. J. Pouch, and Y. Achiba (Mater. Res. Soc. Symp. Proc. 349, Pittsburgh, PA, 1994), p. 251.

33. V. Ivanov, A. Fonseca, J. B. Nagy, A. Lucas, P. Lambin, D. Bernaerts, and X. B. Zhang, Carbon 33, 1727 (1995).

34. K. Hernadi, A. Fonseca, J. B. Nagy, D. Bernaerts, J. Riga, and A. Lucas, Synth. Metals 77, 31 (1996).

35. A. Fonseca, K. Hernadi, J. B. Nagy, Ph. Lambin, and A. Lucas, Carbon 33, 1759 (1995). 
36. R. Sen, A. Govindaraj, and C. N. R. Rao, Chem. Phys. Lett. 267, 276 (1997); also see C. N. R. Rao, R. Sen, B. C. Satishkumar, and A. Govindaraj, Chem. Commun. 1525 (1998).

37. S. Herrere and P. Gadelle, Carbon 33, 234 (1995).

38. M. Endo, K. Takeuchi, K. Kobori, K. Takahashi, H. W. Kroto, and A. Sarkar, Carbon 33, 873 (1993).

39. H. Dai, A. G. Rinzler, P. Nikolaev, A. Thess, D. T. Colbert, and R. E. Smalley, Chem. Phys. Lett. 260, 471 (1996).

40. G. G. Tibbetts, J. Cryst. Growth 66, 632 (1984).

41. R. T. K. Baker, P. S. Harris, R. B. Thomas, and R. J. Waite, J. Catal. 30, 86 (1993).

42. S. Amelinckx, X. B. Zhang, D. Bernaerts, X. F. Zhang, V. Ivanov, and J.B. Nagy, Science 265, 635 (1995).

43. K. Hernadi, A. Fonseca, J. B. Nagy, D. Bernaerts, A. Fudala, and A. A. Lucas, Zeolites 17, 416 (1996).

44. M. Verelst, K. R. Kannan, G. N. Subbanna, C. N.R. Rao, Ch. Laurent, and A. Rousset, J. Mater. Res. 7, 3072 (1992).

45. X. Devaux, Ch. Laurent, and A. Rousset, Nanostruct. Mater. 2, 339 (1993).

46. Ch. Laurent, A. Rousset, M. Verelst, K. R. Kannan, A. R. Raju, and C. N. R. Rao, J. Mater. Chem. 3, 513 (1993).

47. Ch. Laurent, J. J. Demai, A. Rousset, K. R. Kannan, and C. N. R. Rao, J. Mater. Res. 9, 229 (1994).

48. Ch. Laurent, Ch. Blaszczyk, M. Brieu, and A. Rousset, Nanostruct. Mater. 6, 317 (1995).

49. O. Quénard, Ch. Laurent, M. Brieu, and A. Rousset, Nanostruct. Mater. 7, 497 (1996).

50. O. Quénard, E. De Grave, Ch. Laurent, and A. Rousset, J. Mater. Chem. 7, 2457 (1997).
51. V. Carles, M. Brieu, and A. Rousset, Nanostruct. Mater. 8, 529-544 (1997).

52. A. Peigney, Ch. Laurent, F. Dobigeon, and A. Rousset, J. Mater. Res. 12, 613 (1997).

53. Ch. Laurent, A. Peigney, and A. Rousset, J. Mater. Chem. 8, 1263 (1998)

54. A. Peigney, Ch. Laurent, O. Dumortier, and A. Rousset, J. Eur. Ceram. Soc., unpublished.

55. C. N. R. Rao, Chemical Approaches to the Synthesis of Inorganic Materials (John Wiley, Chichester, 1994).

56. J. J. Kingsley and K. C. Patil, Mater. Lett. 6, 427 (1988).

57. K. C. Patil, Bull. Mater. Sci. 16, 533 (1993).

58. S. R. Jain, K. C. Adiga, and V. R. Pai Verneker, Combust. Flame 40, 71 (1981).

59. R. Seshadri, A. Govindaraj, H. N. Aiyer, R. Sen, G. N. Subbanna, A. R. Raju, and C. N. R. Rao, Curr. Sci. (India), 66, 839 (1994).

60. O. Quénard, Doctoral Thesis, Toulouse, 280 pp. (1997).

61. G. A. Jablonski, F. W. Geurts, A. Sacco, Jr., and R. R. Biederman, Carbon 30, 87 (1992).

62. S. Iijima, P. M. Ajayan, and T. Ichihashi, Phys. Rev. Lett. 69, 3100 (1992).

63. N. M. Rodriguez, M. S. Kim, and R. T. K. Baker, J. Phys. Chem. 98, 13108 (1994).

64. W. B. Downs and R. T. K. Baker, J. Mater. Res. 10, 625 (1995).

65. B. C. Satishkumar, A. Govindaraj, and C.N.R. Rao, J. Phys. B 29, 4925 (1996). 